DOI: $10.5216 /$ racs.v4.59218

\title{
La Milpa educativa espacio cotidiano de articulación entre la comunidad y la escuela, en la comunidad p'urhépecha de Cherán, Michoacán, México
}

\author{
Elías Silva Castellón ${ }^{1}$ \\ Ulrike Keyser ${ }^{2}$
}

\section{RESUMEN}

El artículo tiene como base eventos importantes y experiencias particulares del movimiento político de autogobierno en Cherán, Michoacán, México. A continuación, el análisis hace una relación de este movimiento político y sus dinámicas con la propuesta y el trabajo del proyecto de las Milpas Educativas, que ha intentado establecer relaciones fuertes y profundas entre comunidad y escuela, creando prácticas educativas contextualizadas a nivel local para la formación de los niños. Por fin se describe la participación de alumnos en la fiesta de "corpus", evento fundamental para la comunidad de Cherán.

PALABRAS ClAVE: Autogobierno. La escuela. Prácticas educativas.

\section{La Milpa educativa espaço diário de articulação entre a comunidade e a escola, na comunidade $P^{\prime}$ urhépecha de Cherán, Michoacán, México}

\section{RESUMO}

$\mathrm{O}$ artigo tem como base eventos importantes e experiências particulares do movimento político de autogoverno que ocorreu em Cherán, Michoacán, México. Em seguida, a análise faz uma relação desste movimento político e suas dinâmicas com a proposta e o trabalho do projeto Milpas Educativas, que tem tentado estabelecer relações fortes e profundas entre comunidade e escola, criando práticas educativas contextualizadas a nível local para a formação das crianças. Por fim descreve-se a participação de alunos na festa de "corpus", evento fundamental para a comunidade de Cherán.

PALAVRAS-CHAVE: Autogoverno. Escola. Práticas educativas.

\footnotetext{
${ }^{1}$ Doctor en educación por la Universidad Pedagógica Nacional, México. Docente en posgrado, licenciatura, asesor largo tiempo en las Milpas Educativas y en educación básica. Estado de Michoacan, México. E-mail: eliassicp@gmail.com.

${ }^{2}$ Doctora en educación por la Universidad Pedagógica Nacional, México. Coordinadora estatal del proyecto Milpas Educativas. Integrante de la Red de Educación Inductiva intercultural. Docente-investigadora de la Universidad Pedagógica Nacional. Estado de Michoacan, México. E-mail: ulikeyser@ hotmail.com.
} 


\section{Introducción}

La Milpa educativa es un proyecto desarrollado en varios Estados de México, con la finalidad de articular actividades basadas en conocimientos locales con escolares y fomentar el "buen vivir". El punto de partida y de llegada de las actividades escolares es la comunidad. Así, la comunidad brinda sus conocimientos, recursos organizativos y de materia prima para la actividad educativa y recibe, a cambio, niñas y niños formados para mantener y profundizar prácticas y conocimientos comunitarios. En el caso de la comunidad de Cherán, Michoacán, México, los conocimientos y las prácticas locales se vinculan con el tema del movimiento social que inició en abril de 2011 para recuperar la seguridad de sus habitantes, el territorio, los recursos naturales frente a los grupos criminales que operaban en la zona. Parte de su lucha fue la construcción de un gobierno propio basado en usos y costumbres p'urhépechas, que han mantenido desde entonces.

El artículo comparte primero eventos y experiencias de esta lucha y del gobierno propio sin injerencia de partidos políticos como su resultado más visible. Enseguida revisa cómo el equipo que trabaja con el proyecto de las milpas educativas ha tratado de llevar esta experiencia de nuevas relaciones entre las y los que constituyen la comunidad al ámbito educativo. En lo particular, muestra la experiencia de las actividades educativas realizadas en tres centros educativos, uno de preescolar y dos de inicial, que dan cuenta de los aprendizajes logrados mediante esta modalidad educativa alternativa a los programas oficiales, pero compatible con éstos. Las educadoras de los centros educativos se han vinculado con comuneras y comuneros para llevar a cabo sus actividades educativas fuera y dentro de la escuela, con bases firmes en investigaciones locales y el calendario socionatural como elemento del Método Inductivo Intercultural (MII).

Nos estamos basando en observaciones participantes durante el movimiento social de Cherán y el trabajo en las Milpas educativas, registros de las conversaciones en reuniones de trabajo con las educadoras y talleres de autoformación.

Dossiê Práticas de bem viver: diálogos possíveis entre o Núcleo Takinahakỹ e Milpas Educativas

R. Articul.const.saber, 2019, v.4: e59218 


\section{1 ¿Aprendizaje continuo en la Milpa educativa? Los bienes llamados conocimientos son materias primas vinculantes con otros conocimientos}

"Es un hervidero de gente, todos pálidos y con sus rostros cubiertos", escuché, dijo una señora al pasar. Es el 15 de abril de 2011. Entonces Cherán hirvió al culminar la serie de agravios contra sus habitantes y el saqueo del territorio y sus recursos, sobre todo del bosque, por más de una década. Al arrasar con el bosque el interés no sólo era la madera, era también la empresa del "oro verde", el aguacate, supuestamente para generar riqueza. La empresa dice a los campesinos "vas a tener trabajo, réntame tus tierras para sembrar papa y de paso tienes contrato" para trabajarle a la empresa. La idea de los delincuentes era un negocio redondo y duradero.

También, ese 15 de abril se evidenció lo que toda la comunidad sabía, porque se pusieron de manifiesto la corrupción, la deshonestidad y las alianzas criminales en todos los niveles de las instancias gubernamentales de seguridad y de justicia con el crimen depredador del territorio. Secuestros y asesinatos, extorsiones. Era necesaria la defensa por la vida para recuperar la seguridad y dignidad de los habitantes. Coraje y rabia de las mujeres y de los hombres, que juntos resistieron, volviendo a hacer comunidad.

En el fondo seguían todo el tiempo las relaciones entre las familias con sus prácticas de relación colaborativa y cooperante, sin embargo fracturadas a causa de la división generada en la comunidad por los partidos políticos que solamente a sus más "allegados" ofrecían distintos tipos de apoyos materiales. En este momento los conocimientos y las prácticas locales tradicionales vinculadas al movimiento social emergente resultaron indispensables. Allí estaban los usuarios de esta tradición: cubrirse el rostro para descubrir de nuevo que solo juntos era posible la defensa y la persistencia de la comunidad. Pero también fue necesario vitalizar las instituciones con que cuenta la comunidad, las que no compiten con los poderes ya instaurados, facticos y que corresponden luego a otros propósitos menos a los de la comunidad.

La vida social, familiar y personal también se redescubrió en medio del "hervidero". Haciendo omisa la retórica de que el Estado era el encargado de la seguridad y la justicia. La organización propia de la comunidad resultó más eficaz, segura y eficiente para reorganizarse en la búsqueda de justicia, seguridad, restitución del territorio y reconstrucción del tejido social. Estos objetivos hasta hoy son lema, guía en sus gobiernos.

Dossiê Práticas de bem viver: diálogos possíveis entre o Núcleo Takinahakỹ e Milpas Educativas

R. Articul.const.saber, 2019, v.4: e59218 
Se retoman las instituciones tradicionales de larga vigencia que el Estado anulaba y sólo bajo la luz de normas y tratados internacionales con la insistencia de la comunidad y especialistas en la materia surtieron efecto. Ejemplo de la organización y movilización interna es la Ronda comunitaria, cuya base es el comunero, la comunera de cada barrio. La comunidad volvió a entender qué bien se vive bajo la voluntad del pueblo con base en sus instituciones muy propias, que mantienen la cohesión social utilizando sus principios y prácticas culturales. Este espacio de poder emana de las asambleas comunitarias y de barrio.

Se ha repetido que solo funciona bien el tipo de gobierno adoptado por el estado mexicano, por lo tanto, sufre el Gobierno comunal actos de arrinconamiento y exclusión en términos administrativos y de "normatividad". Aquí se muestra la cohesión comunal frente al orden del otro.

Para eficientar la organización y la vigilancia en defensa del bosque en su sentido colectivo, se inspiró en conocimientos ancestrales y también de los conocimientos del sistema escolar al crear el vivero comunal. Se trata de una obra con el sentido de acción y colaboración comunal de distribución y desarrollo, concibiendo a los comuneros como el motor que trabaja para la reconstitución del territorio respondiendo a criterios comunales. Son elementos de un modo de vivir diferente.

\section{2 ¿Cómo es que bajo el "hervidero" la Milpa educativa pudo articular entre la comunidad y la escuela?}

Bajo esta forma de trabajo el equipo de educadoras ha logrado avances en la sistematización de las experiencias y a la vez profundizó en el Método Inductivo Intercultural para mejorar las prácticas docentes y la relación con la comunidad.

El trabajo constante, sistemático y planeado desde hace más de siete años ha generado un equipo de confianza y apoyo, que invierte tiempo y dedicación a la colaboración y interaprendizajes mutuos. Una relación 'a descubierta' lleva a la vinculación de educadoras con comuneras y comuneros para sus actividades educativas fuera y dentro de la escuela.

El trabajo, el oficio, el cargo, la comisión que se le delega o toma el comunero, la comunera, hace volver la vista a estos acontecimientos cotidianos realizados por gente trabajando

Dossiê Práticas de bem viver: diálogos possíveis entre o Núcleo Takinahakỹ e Milpas Educativas

R. Articul.const.saber, 2019, v.4: e59218 
bajo el sol. Ha 'caído' y ha resurgido la actividad educativa dentro y fuera de la escuela. El hacer en la milpa es referencia para la construcción de conocimiento y también es manera de educarnos y poco a poco se comprende que la escolarización tampoco es determinante para saber quién esta educado o no. Ahora, más bien es una constante necesidad de las docentes vincular el saber de la comunidad con el currículum del sistema educativo. Lo que permite realizar ejercicios de planeación con contenidos locales. Claro, esto a partir de trabajar con el MII.

Recojo un decir, frecuente al menos durante cierta etapa de la educación básica en regiones indígenas, y que en la comunidad todavía se escucha: "no vayas (dirigido al niño, a la niña) a la escuela, mejor acompáñame a la uechantani ${ }^{3}$ o a la ayudanza" en un evento festivo. Esta frase deja fuera de sí a los docentes; para la escuela faltar a clases por una fiesta es el principio del fracaso y, para el sistema educativo es una de las razones de ocupar los últimos lugares en el ranking de los organismos internacionales dedicados a observar y promover lo que necesita la educación en los países "pobres" desde el punto de vista de los "ricos". (Silva, 2017, p. 51)

Ante este tipo de situaciones el equipo de las milpas educativas subraya su convencimiento pleno de que ese saber de la comunidad es necesario en la escuela. Como lo es la siembra del maíz, y todo lo que conlleva esta práctica social de producir alimentos, tradiciones y cultura.

En el paisaje del hacer dentro de la comunidad el continuo 'uechantani' persiste y a todos les toca su momento. ¿Es posible un aprendizaje persistente? Más que un sí, digo, es un requisito necesario, antecede para seguir con esos bienes llamados conocimientos y no solo son un 'bien' sino son materias primas vinculantes con otros conocimientos que puede ofrecer la escuela.

Las prácticas comunitarias y los conocimientos implícitos en ellas crean la necesidad de saber de las diferentes ciencias y conocer las que brinda la escuela. Explicar apoyado con ciencias como biología, la química por qué las plantas de la milpa tienen colores, fuertes unos, otros con coloración débil, o la presencia de 'animalitos' que comen las hojas de la milpa.

\footnotetext{
${ }^{3}$ Uechantani, palabra Purhépecha que tiene sentido de devolver, reciprocar el apoyo recibido, aunque este apoyo aún no se haya recibido de manera directa.
}

Dossiê Práticas de bem viver: diálogos possíveis entre o Núcleo Takinahakỹ e Milpas Educativas

R. Articul.const.saber, 2019, v.4: e59218 
Un tercer elemento indispensable es la investigación en la comunidad como actividad básica para las actividades comunitarias-escolares. Porque hace posible la claridad en el enfoque, el método y las herramientas para obtener las respuestas que permiten solucionar problemáticas de la milpa no sólo desde lo técnico-científico, sino comprender por qué la importancia económica, social y cultural de la milpa aun en la comunidad y como este fuerte vínculo de las familias con la tierra permanece a pesar de que los hijos están en las escuelas, y que sin embargo la escuela siempre intenta excluirlas porque 'no son tan importantes, eso ya lo saben los niños'.

La investigación, es decir la curiosidad planeada, organizada y que se va organizando en torno al por qué se hace determinada actividad, su pertinencia y sentido en la escuela, ha cambiado el hablar por el hacer hacia una posibilidad de interaprendizaje, basado en el acompañamiento continuo por expertas de la comunidad.

Menciono de nuevo que el MII se fragua en la actividad, pero sobre todo las docentes siempre buscan nuevos conocimientos y volvieron la investigación una parte habitual de su ser docente y comunera.

\section{3 ¿Cómo se articulan investigación y prácticas comunitarias con educativas?}

Una evidencia de esta articulación consistió en la participación de niñas y niños en la fiesta más representativa de la comunidad, el Corpus.

De acuerdo con los objetivos del proyecto de las Milpas educativas, las educadoras de los tres centros educativos centraron en 2018 sus actividades como colectivo y en coordinación con comuneras y comuneros en un evento emblemático de la comunidad que muestra en la práctica de conocimientos y saberes comunitarios la articulación entre humanos y naturaleza y les otorga un papel particular a niñas y niños: la fiesta de Corpus Cristi, o llamada "Corpus" a nivel local y regional, porque se practica en toda la región p'urhépecha.

Su sentido originario es el agradecimiento de los humanos a la naturaleza por los recursos que ofrece para que estos los transformen mediante su trabajo con la finalidad de satisfacer sus propias necesidades. Así, en cada comunidad se hace énfasis en los productos característicos de la localidad.

Dossiê Práticas de bem viver: diálogos possíveis entre o Núcleo Takinahakỹ e Milpas Educativas

R. Articul.const.saber, 2019, v.4: e59218 
En Cherán se destaca lo que ofrece sobre todo el bosque (miel de abeja, hongos y otras plantas, animales de caza), pero también el campo (maíz). Como uno de los elementos religiosos católicos destaca San Anselmo, patrón de las abejas silvestres, que se coloca, representado en varias imágenes, desde ocho días antes de la fiesta en determinados puntos de la orilla de la comunidad, donde lo visitan las y los comuneros para convivir con él y entre ellos.

Las primeras actividades de la parte p'urhépecha de la fiesta se desarrolla desde aproximadamente tres semanas antes en las calles de la comunidad, donde niñas y niños ofrecen alimentos típicos preparados en casa, en tamaños muy pequeños. En varios momentos de la fiesta llaman la atención objetos de este tamaño, hasta de miniatura: la imagen del santo es de aproximadamente $30 \mathrm{~cm}$, las abejas y sus larvas son los animales más pequeños del bosque que se aprovechan por los humanos. Este tipo de alimentos y otros productos llegan a ser "cambiados" por sal o maíz en lugar de dinero.

El evento central de la fiesta es un recorrido por determinadas calles del pueblo, donde jóvenes y niños llevan en sus espaldas unos cargamentos llamados katárakuas, mientras mujeres jóvenes y niñas bailan al son de la melodía típica de esta fiesta. Las katárakuas consisten en una estructura de madera sobre la cual colocan panales de abejas silvestres, plantas y animales del bosque, adornados con ramas y hojas de un árbol específico (cirimo).

Las y los integrantes de las Milpas educativas participaron en tres momentos de esta fiesta: 1. Acompañaron a San Anselmo desde la casa del carguero (jefe de familia que hospeda la imagen del santo durante todo un año y recibe a las personas que lo visitan y veneran) a un lugar en la orilla de la comunidad; 2. Elaboraron katárakuas (en un centro escolar); y 3. Llevaron a cabo el recorrido por calles del pueblo. En todo momento se contó con especialistas de la comunidad en los conocimientos y saberes requeridos, y con la participación de madres y padres de familia.

Las niñas y los niños se acercaron a distintos tipos de aprendizajes y áreas de conocimiento. Los aprendizajes fueron significativos en el sentido de haber aprendido observando y haciendo y aplicados los nuevos conocimientos en las diversas prácticas (Díaz Barriga, 2003; Rogoff, 1993).

Durante la primera actividad, conocieron una parte de la comunidad y su nombre en p'urhépecha, se relacionaron con personas desconocidas al rezar con ellas y ofrecerles comida 
que habían preparado junto con sus madres y abuelas. Por la iniciativa de las maestras participaron algunas madres de familia por primera vez en este tipo de actividad. Algunos niños y niñas tuvieron oportunidad de abrazar a la imagen del santo, un acto de gran devoción y emoción.

La elaboración de las katárakuas fomentó la capacidad de observación entre niñas y niños, también varias madres y padres de familia realizaron esta actividad por primera vez. Había especialistas que orientaron los diferentes pasos en la elaboración, pero también contó mucho su experiencia como observadores de cómo familiares suyos habían hecho katárakuas en años pasados. Lo que normalmente es trabajo de hombres ahora también lo desempeñaron mujeres, aconsejándose mutuamente.

Mientras las niñas se limitaron más a ser observadoras, varios niños tomaron la iniciativa en los pasos y momentos que sintieron apropiados para colaborar. Apoyaron a llevar a sus madres los materiales que ocupaban en su momento, adornaron con flores donde se necesitaba. El especialista les comentó dónde se encuentran los panales de las abejas en el bosque, cómo hay que subir al árbol para bajarlos, cuáles son los peligros y cómo cuidarse de los piquetes de abejas. Al cargarse la katárakua los niños aprendieron cómo sujetar y cargarlas para, finalmente, saber bailar con esta carga en la espalda sin perder el equilibrio.

La culminación de las actividades fue el recorrido por las calles de la comunidad, donde los niños bailaron cargando las katárakuas, y también las niñas al ritmo de una pequeña orquesta con las melodías típicas de esta fiesta. Por los peligros que representaba una participación de niños pequeños en el recorrido de jóvenes y adultos, se realizó esta actividad un día antes de la fiesta y con panales sin abejas.

De esta manera se transgredió la regla del Método Inductivo Intercultural, que todas las actividades deben realizarse en tiempos, espacios y con las personas que suelen participar en el contexto comunitario. Sin embargo, en este caso, tanto niñas como niños están acostumbrados a “jugar al Corpus", donde utilizan materiales que tienen a la mano para representar esta fiesta e introducirse a ella mediante su propia iniciativa.

Lo que por supuesto resalta la posibilidad de interaprender comunicando, y en una interacción de la escuela con la comunidad, y con otros actores:

Dossiê Práticas de bem viver: diálogos possíveis entre o Núcleo Takinahakỹ e Milpas Educativas R. Articul.const.saber, 2019, v.4: e59218 
- Con la familia, el barrio, las y los rezanderos, la familia del cargo, etc.

- Desarrollando y practicando actividades que luego se acompañan desde la familia, ahora la experiencia fue a partir de la escuela donde acompañaron y enseñaron de otro modo la madre, el padre o ambos, alguien de la familia o una experta, luego con observaciones y ánimos de las docentes.

- Viviendo y comprendiendo las fases de la vida y las temporadas que acontecen antes y después del periodo de determinada actividad, por ejemplo del Corpus.

El recorrido causó mucha admiración e interés en la población en general y también entre maestras y maestros de otros centros educativos que no están formados con el MII. El interés entre gran parte del magisterio por actividades comunitarias como momentos y espacios naturales de aprendizaje que luego se fortalecen en la escuela, está creciendo debido a la existencia de programas alternativos al que edita y distribuye la Secretaría de Educación Pública a nivel nacional.

Las demandas y luchas del magisterio indígena, organizado en una vertiente disidente del Sindicato Nacional de los Trabajadores de la Educación (SNTE), llamado Coordinadora Nacional de los Trabajadores de la Educación (CNTE), ha llevado al diseño de programas alternativos por las y los mismos docentes. Desde 2018 se está trabajando con este tipo de programas en regiones de población originaria en los estados de Chiapas, Oaxaca y Michoacán, donde se sigue negociando su reconocimiento oficial.

En el caso de la comunidad de Cherán, por su gobierno "basado en usos y costumbres", se cuenta con otro programa educativo más. Se diseñó con la intención de adecuar contenidos y actividades escolares a las necesidades y expectativas educativas que demanda este tipo de gobierno, es decir, trabajar con conocimientos y prácticas p'urhépechas que fortalecen la autodeterminación frente a la dominación de intereses ajenos a la comunidad.

Por lo tanto, las educadoras que trabajan con el MII en las Milpas educativas combinan varios programas: Programa de Educación Preescolar de 2011 (programa nacional); Marco Curricular de la Educación Inicial Indígena de 2010 (programa nacional); Proyecto educativo de la comunidad de Cherán K'eri de 2013 (local); Programa de Educación para los Pueblos Originarios de Michoacán (PEPOMICH) de 2017 (sindical, estatal). Aunque los programas 
dirigidos específicamente a población originaria también hacen énfasis en el uso de la lengua y los conocimientos propios, sólo el MII implica constante investigación, la participación de personas mayores y expertos, y la importancia del territorio como base para las políticas de autodeterminación.

A pesar de la existencia de los programas alternativos, la mayoría de las y los docentes que pertenecen al sistema de educación indígena, no están dispuestos a invertir más tiempo de lo acostumbrado en la preparación y realización de actividades comunitarias con sus alumnos. En este sentido, las compañeras que trabajan con el MII en las Milpas educativas constituyen todavía una excepción.

\section{Reflexiones finales}

A partir de los aprendizajes logrados en las prácticas educativas y el hacer comunitario concluimos que para lograr la articulación de conocimientos y significados, los educadores deben procurar el desarrollo integral de sus alumnos como ciudadanos activos al interior de la comunidad donde viven, sin saturarlos de información abstracta, fragmentada e inservible (Keyser, Silva, Hernández y Bertely, 2012, p. 22)

Pudiéramos decir que esto significa 'buen vivir' o sencillamente vivir la comunidad, nuestra comunidad viva y sin distancias de la naturaleza. Es imprescindible volver a la cercanía, evitar fisuras de interés depredador, monocultivo, porque pierdan sentido y vista de que la naturaleza y la comunidad son espacios, lugares de aprender. Esto requiere retomar las maneras de cómo se hacía comunidad y se educaba antes, ahora junto con nuevos enfoques, métodos y herramientas. Con ello se llega a la creación de materiales didácticos cuya base es la sistematización del conocimiento para propiciar y dar formas a los aprendizajes desde la posibilidad y vida de la comunidad.

Dossiê Práticas de bem viver: diálogos possíveis entre o Núcleo Takinahakỹ e Milpas Educativas

R. Articul.const.saber, 2019, v.4: e59218 


\section{Referencias}

Diaz Barriga Arceo, F. Cognicion situada y estrategias para el aprendizaje significativo. Revista Electrónica de Investigación Educativa, 5(2). Recuperado de http://redie.ens.uabc.mx/vol5no2/contenido-arceo.html. (2003).

Keyser, U., Silva, E., Hernández, M. y Bertely M. Guía para sembrar el método inductivo intercultural en comunidades y escuelas. Pueblos p'urhépecha. En Bertely, M. (Coord.). Tarjetas de Auto-Interaprendizaje (Chiapas, Michoacán, Oaxaca y Puebla). México: CIESAS, UPN. 2012.

Rogoff, B. Aprendices del pensamiento. El desarrollo cognitivo en el contexto social. Barcelona, España: Paidós. 1993.

Silva Castellón, Elías. Espacios, aspectos e intereses de la educación desde la manera propia en Cherán. En A Colín (Coord.). Cherán K'eri. 5 años de autonomía. Querétaro, México: En cortito que's pa largo. 2017.

Submetido em 27 de junho de 2019.

Aceito em 05 de agosto de 2019.

Publicado em 08 de agosto de 2019.

Dossiê Práticas de bem viver: diálogos possíveis entre o Núcleo Takinahakỹ e Milpas Educativas

R. Articul.const.saber, 2019, v.4: e59218 